\title{
O PRINCÍPIO DA PROPORCIONALIDADE À LUZ DA TEORIA DOS LIMITES DOS LIMITES: CRITÉRIOS DE ANÁLISE DE RESTRIÇÕES A DIREITOS FUNDAMENTAIS
}

\author{
MARCELOSCHENK DUQUE ${ }^{1}$ \\ ISABELA MOREIRA ANTUNES DO NASCIMENTO ${ }^{2}$
}

\begin{abstract}
Resumo: Técnicas de direito comparado vêm sendo cada vez mais utilizadas pelos tribunais brasileiros, na solução de conflitos que envolvem normas de direitos fundamentais. Neste contexto, o objetivo deste estudo é investigar o princípio da proporcionalidade à luz da Teoria dos Limites dos Limites, técnica desenvolvida no curso da doutrina e jurisprudência alemãs, como critério para a análise das restrições a direitos fundamentais. O foco da análise é a contextualização da estrutura dos direitos fundamentais enquanto normas principiológicas, a partir dos conflitos delas decorrentes. A investigação parte do pressuposto de que a partir da estrutura vaga dos direitos fundamentais, conflitos costumam ocorrer com maior frequência, em relação às normas de conteúdo mais concreto. Esse é o motivo pelo qual a busca por critérios racionais de solução desses conflitos é uma meta necessária à interpretação constitucional. A análise justifica-se pela importância crescente que a interpretação do âmbito de proteção dos direitos fundamentais adquire no cenário da cultura jurídica contemporânea. O estudo adota o método de pesquisa dedutivo combinado com técnica de revisão bibliográfica e jurisprudencial.
\end{abstract}

Palavras-Chave: Direitos fundamentais; Núcleo essencial; Teoria dos Limites dos Limites; Princípio da Proporcionalidade.

\footnotetext{
${ }^{1}$ Doutor em Direito do Estado pela UFRGS/ed. Ruprecht-Karls-Universität Heidelberg, Alemanha. Professor titular da Escola da Magistratura Federal do Estado do Rio Grande do Sul - ESMAFE/RS. Professor da Faculdade Dom Bosco de Porto Alegre. Professor da Escola Superior de Advocacia da OAB/RS.

2 Mestranda em Direito pela Universidade Católica de Petrópolis-UCP.
} 


\title{
THE PRINCIPLE OF PROPORTIONALITY IN THE LIGHT OF THE LIMITS THEORY: CRITERIA FOR ANALYSIS OF RESTRICTIONS ON FUNDAMENTAL RIGHTS
}

\begin{abstract}
Techniques of comparative law have been increasingly used by Brazilian courts in the resolution of conflicts involving fundamental rights norms. In this context, the objective of this study is to investigate the principle of proportionality in the light of Limit Limits Theory, a technique developed in the course of German doctrine and jurisprudence, as a criterion for the analysis of restrictions on fundamental rights. The focus of the analysis is the contextualization of the structure of fundamental rights as principles, starting from the conflicts arising from them. The investigation starts from the assumption that from the vague structure of fundamental rights, conflicts usually occur more frequently, in relation to the rules of more concrete content. This is why the search for rational criteria for solving these conflicts is a necessary goal for constitutional interpretation. The analysis is justified by the growing importance that the interpretation of the scope of protection of fundamental rights acquires in the scenario of the contemporary legal culture. The study adopts the method of deductive research combined with a bibliographical and jurisprudential review technique.
\end{abstract}

KEYWORDS: Fundamental rights. Essential core. Theory of Limits of Limits. Principle of proportionality. 


\section{O PRINCÍPIO DA PROPORCIONALIDADE À LUZ DA TEORIA DOS LIMITES DOS LIMITES}

\section{INTRODUÇÃO}

Os direitos fundamentais, na condição de normas que pautam as liberdades individuais e coletivas, afirmando-se como pressupostos para uma vida digna, vem ganhando significado crescente na cultura jurídica contemporânea. A luta que costumava envolver a conquista por novos direitos acaba, de certo modo, dando lugar para uma luta de manutenção de direitos conquistados, que não raro têm sua existência ameaçada em cenários de crise econômica ou institucional.

Acreditar que os direitos fundamentais seriam absolutos acaba por não contribuir para sua efetividade. Isso porque a natureza das coisas, bem como a necessidade de fruição simultânea por parte de titulares com interesses distintos, acaba por impor a necessidade, quase que inevitável, de restrições a bens jurídicos de incontestável hierarquia. É neste contexto que surge a presente investigação: propor uma discussão acerca do significado prático do princípio da proporcionalidade à luz da Teoria dos Limites dos Limites, como critério para a verificação da constitucionalidade das restrições a direitos fundamentais impostas pelo poder público ou por particulares.

A relevância do tema reside, justamente, na constatação de que cenários de crise acabam impactando, invariavelmente, na eficácia dos direitos fundamentais. Na condição de normas principiológicas, dotadas de elevado grau de abstração, a interpretação que incide sobre o âmbito de proteção dos direitos fundamentais acaba ganhando contornos diversos, o que dificulta a busca de soluções racionais, no que tange à avaliação da compatibilidade de restrições a esses direitos com a Constituição, frente à necessidade de preservação do seu núcleo essencial.

O marco referencial teórico da investigação está contido em obras de autores nacionais (BARROSO, 2014, p. 118; DUQUE, 2014, p. 122ss; BONAVIDES, 2017, p. 269), que centram seus esforços no estudo dos direitos fundamentais, bem como em autores de direito comparado (DWORKIN, 2016, p. 31), em particular de matriz jurídica alemã (ALEXY, 1994, p. 125), considerando a expertise que os juristas alemães desenvolveram no curso da cultura que envolve os direitos fundamentais e suas repercussões para a realização da dignidade humana.

O trabalho se sustenta em dois capítulos, cada qual com três subitens. O primeiro aborda a Teoria dos Limites dos Limites, sob a perspectiva e estrutura dos direitos fundamentais, dos conflitos a eles inerentes, bem como da necessidade de proteção do seu núcleo essencial, com escopo na análise da dignidade humana. Já o segundo, analisa a estrutura do 


\section{REVISTA ESTUDOS INSTITUCIONAIS}

JULHO/DEZEMBRO - ISSN 2447-5467

Princípio da Proporcionalidade sob os critérios da adequação, necessidade e proporcionalidade em sentido estrito à luz da referida teoria.

No que tange às considerações metodológicas, recorre-se à técnica de revisão bibliográfica e jurisprudencial, de natureza qualitativa e exploratória, visto que proporciona maior proximidade com o problema para defini-lo e, ao mesmo tempo, aprimorar concepções que geram reflexão.

\section{TEORIA DOS LIMITES DOS LIMITES}

\section{Direitos Fundamentais Enquanto Expressão de Normas Principiológicas}

O positivismo jurídico foi a importação do positivismo filosófico para o Direito, na intenção de criar uma ciência jurídica com pretensão de completude e com características análogas às ciências exatas e naturais, pautando-se sempre pelo formalismo. Ao priorizar a objetividade científica, com ênfase na realidade observável e não na especulação filosófica, afastou-se o Direito da moral e dos valores, entendendo que não seria adequado tratar de assuntos como legitimidade e justiça. Nesta visão o Direito seria regra, ato emanado pelo Estado com coatividade e imperatividade, cuja ciência, como todas as demais, deveria fundar-se em juízos de fato, visando ao conhecimento da realidade, e não em juízos de valor, representantes de tomada de posição diante da realidade (BARROSO, 2014, p. 118).

Para o Direito, diferentemente de outras vertentes, não é suficiente a adoção de uma postura apenas descritiva da realidade, que apenas explicita o que existe, tendo, ao contrário, a pretensão de atuar sobre ela, transformando-a de modo que o ideal de absoluta neutralidade e objetividade não é realizável. Há sim, e deve haver, um vínculo entre o sujeito e o objeto em análise, ou seja, entre operador, norma e realidade (BARROSO, 2014, p. 119). Se por um lado é correto afirmar que um panorama em face de todas as questões valorativas é improvável de ser obtido (ZIPPELIUS,1962, p. 13) não se pode perder de vista que a consciência jurídica é, acima de tudo, uma consciência de valores na vida social, à medida que é justamente na vida cultural que se insere o Direito (SILVEIRA, 1991, p. 2ss). Diante da insuficiência do positivismo jurídico desenvolve-se, então, o pós-positivismo (BONAVIDES, 2017, p. 269), que abarca valores, princípios, regras e aspectos da chamada nova hermenêutica e da teoria dos direitos fundamentais. 


\section{O PRINCÍPIO DA PROPORCIONALIDADE À LUZ DA TEORIA DOS LIMITES DOS LIMITES}

No ponto, os princípios ganham reconhecimento e normatividade e passam a ser a síntese dos valores abrigados no ordenamento jurídico, refletindo, explícita ou implicitamente a cultura jurídica contemporânea. Em matéria de direitos fundamentais, particularmente em sede de jurisdição constitucional, preceitos sobre valores podem ser reformulados em preceitos sobre princípios sem que, com isso, haja necessariamente uma perda de conteúdo (ALEXY, 1994, p. 125). Eles guiam o intérprete, integram e harmonizam o sistema, suprindo lacunas, atenuando conflitos aparentes e apontando os fins morais de dada sociedade (BARROSO, 2014, p. 122).

Longo debate se trava acerca da distinção entre princípios e regras como subdivisões da norma jurídica. Não é o foco do presente estudo aprofundar esta distinção, mas sim compreender que, pelo fato de os princípios possuírem um grau de abstração superior ao das regras (AVILA, 2006, p. 48), o seu manejo interpretativo costuma ser muito mais complexo. Com base nisso, afirma-se que os direitos fundamentais são normalmente formulados por meio de princípios jurídicos, com conteúdo marcado pela vagueza e abstração. Não fosse assim, dificilmente poderiam cumprir as funções a que se destinam, de acordo com a sua natureza, já que não se destinam a fixar uma única forma de conduta possível, mas sim uma conduta orientada a valores reconhecidos e garantidos pela ordem constitucional como um todo (DUQUE, 2014, p. 133).

É por essa razão que se pode afirmar que na condição de normais principiológicas, que ordenam que algo seja realizado na maior medida possível, de acordo com as possibilidades fáticas e jurídicas de cada caso (ALEXY, 1994, p. 75ss), os direitos fundamentais são guindados ao texto constitucional em consonância com o horizonte valorativo concreto, por ocasião da promulgação da Constituição (DI FABIO, 2006, p. 51). Isso significa a Constituição diz muito sobre o estado de desenvolvimento cultural de um país (HÄBERLE, 2006, p. 621ss), bem como o grau de respeito às suas normas.

A partir desta perspectiva principiológica, os direitos fundamentais são reconhecidos à luz de um duplo caráter, marcado por uma dimensão objetiva, diversa da clássica concepção de direitos subjetivos públicos, oponíveis pelos seus titulares somente em relação ao Estado, que encontra a sua expressão no fortalecimento da força de vigência dos próprios direito fundamentais (MANGOLDT; KLEIN, 1957, p. 93), concepção que restou desenvolvida pela doutrina e jurisprudência em larga escala (DUQUE, 2014, p. 122ss). Esse duplo caráter reside justamente na constatação de que os direitos fundamentais passam a ser 


\section{REVISTA ESTUDOS INSTITUCIONAIS}

JULHO/DEZEMBRO - ISSN 2447-5467

compreendidos e estudados tanto como direitos subjetivos individuais quanto como elementos objetivos fundamentais da comunidade, constituindo essa abordagem em uma das inovações mais importantes do direito constitucional contemporâneo (GRIMM, 1991, p. 221). O termo objetivo aponta para a função desses direitos como princípios superiores, verdadeiros componentes estruturais da ordem jurídica (SARLET, 2012, p. 143).

Com base nas considerações preliminares já se pode delinear que a partir do paradigma jusfilosófico pós-positivista, destaca-se a força normativa da Constituição em que se empreende uma leitura moral do Direito, indo além da frieza eventual do texto da norma, sem, contudo, desprezar o Direito posto. Parte-se do pressuposto de que de que em todos os casos mais ou menos problemáticos são necessárias valorações que não podem ser tomadas independentemente do material dado e dotado de autoridade (ALEXY, 1994, p. 498ss), isto é, da Constituição e da legislação vigente.

O motivo, para tanto, é claro: compreender e interpretar significa conhecer e reconhecer um sentido vigente (GADAMER, 1990, p. 333). Refutam-se arbitrariedades e abusos, mas não se trata a Constituição como norma simbólica - expressão de uma folha de papel - o que lhe conferiria mera conotação semântica, dentro da perspectiva sociológica de Lassalle (2001, p. 17ss). Trata-se de visão incompatível com a força normativa da Constituição, que ordena que a situação por ela regulada torne-se efetiva, exatamente na realidade onde está inserida (HESSE, 1959, p. 08).

A partir da superação da dogmática jurídica tradicional pela teoria crítica, a lei não mais é vista apenas como expressão superior da razão, assim como não é, necessariamente, sinônimo de justiça. O sistema jurídico não é autossuficiente, mas interdisciplinar, por vezes vinculando-se à filosofia ou à sociologia, por exemplo (BARROSO, 2014, p. 111). Não há mais um direito puro e idealizado assim como o Estado não é um árbitro imparcial, cabendo ao juiz, por vezes, um papel criativo (DWORKIN, 2016, p. 31). Isso indica que ao jurista não basta uma visão ingênua e perfeccionista do Direito. Busca-se equilíbrio, mas sem pretensão de completude. Passa-se, então, a analisar os inevitáveis conflitos entre direitos fundamentais enquanto normas principiológicas que são.

\section{Os Direitos Fundamentais e sua Tendência ao Conflito}

Quando se trabalha com normas marcadas por elevado grau de abstração, os desafios interpretativos aumentam, significativamente. A 


\section{O PRINCÍPIO DA PROPORCIONALIDADE À LUZ DA TEORIA DOS LIMITES DOS LIMITES}

abertura semântica das normas convida o seu aplicador a propor um leque de interpretações possíveis. Aqui, problemas de insegurança jurídica costumam surgir com mais frequência do que em outros âmbitos. Nessa perspectiva, o desafio consiste em não se tornar arbitrário na busca de uma concepção particular de justiça. Tarefa difícil, em um cenário onde a tentação gerada pelo poder de decidir sobre a vida das pessoas costuma despertar sentimentos dos mais diversos. O que importa é que o recurso à determinação dos fins supremos do ordenamento jurídico não pode, em nenhum momento, servir de meio para ludibriar a Constituição, no instante em que a sua respectiva eleição pode representar um interesse discricional pretensamente superior, cuja hierarquia é, em geral, controvertida (HESSE, 1999, p. 33). Afinal, não se pode perder de vista que a segurança jurídica, para além de um valor positivado, afirma-se como uma noção inerente à própria ideia de Direito, levando-se em conta que sem um mínimo de certeza e de atitude voltada ao rechaço à arbitrariedade, não se pode, a rigor, falar em sistema jurídico (ÁVILA, 2011, p. 85ss).

Logo, a Constituição não pode ser abandonada por conta da insegurança gerada por uma luta permanente de poderes e de opiniões que, em sua argumentação, passam longe de uma base comum (HESSE, 1999, p. 33). A partir daí, percebe-se que os ideais de neutralidade e objetividade absoluta são impossíveis no campo do Direito. Não há jurista imune às influências sociais ou mesmo às complexidades pessoais. Ciente de que o Direito se afirma como uma ciência humana e não de ficção, a Constituição é uma base de escolha que não pode ser desprezada, uma moldura a partir da qual devem orientar-se caminhos possíveis. É nesse contexto que os conflitos entre direitos fundamentais devem ser analisados e resolvidos.

Não há como elaborar um sistema normativo perfeito a partir do qual se poderia resolver as colisões com simples subsunção do fato à regra, em razão das lacunas legislativas inevitavelmente existentes ou, ao contrário, da existência de fundamentos diversos para o mesmo caso. Nesses termos, existe uma necessária abertura do Direito, considerando que quando se parte de um amplo suporte fático para os direitos fundamentais, inevitavelmente, aumenta-se a chance de colisão. É justamente neste ponto que o princípio da proporcionalidade adquire relevância, na condição de critério racional do exame das restrições impostas aos direitos fundamentais (BARROSO, 2014, p. 262).

Na realidade da vida, não se deve tratar os direitos fundamentais de forma absoluta, pelo fato de que a definição do ponto em que um termina e o outro começa não pode ser estabelecida sem a devida cautela. $\mathrm{O}$ 


\section{REVISTA ESTUDOS INSTITUCIONAIS}

JULHO/DEZEMBRO - ISSN 2447-5467

problema é que todos nós somos titulares dos mesmos direitos, dividimos os mesmos espaços e, como se não bastasse, costumamos recorrer simultaneamente a esses direitos. Isso significa que a temática da colisão é, ao fim e ao cabo, uma questão inerente à própria estrutura dos direitos fundamentais. Na prática da vida, os direitos fundamentais devem ingressar em constante ponderação de interesses, visando à proteção de bens individuais e coletivos, na maior medida possível. A questão é que se dois direitos que acabam por entrar em conflito forem considerados absolutos, eles acabarão por eliminar a própria natureza da ponderação, pois ponderar significa, na prática, ceder na busca de uma otimização. Quem se considera absoluto, não cede espaço, não admite recuar.

Em razão da complexidade e pluralismo, traços marcantes da sociedade atual, busca-se na Constituição abrigo a diversos interesses e valores que por vezes se chocam. Assim, a melhor saída é acreditar que todos os direitos fundamentais, independentemente da sua relevância, admitem restrições em diferentes graus, de acordo com as circunstâncias do caso concreto. Por serem tratados como princípios, situações de conflito resolvem-se pela ponderação em que se restringe um interesse pela primazia de outro (LERCHE, 1961, p. 130ss). Neste viés é necessário protegê-los contra abusos tanto por parte do legislador quanto pelos intérpretes, fornecendo parâmetros para que tais conflitos possam ser resolvidos dentro de um ambiente de racionalidade.

Essa realidade traz consigo amplas consequências para a jurisdição constitucional, que podem ser resumidas na constatação de uma ampliação os espaços de discricionariedade jurídico-constitucionais, justamente pela indissociável necessidade de ponderação de interesses opostos em face de normas de conteúdo vago e abstrato, que, não raro, exprimem interesses conflitantes entre posições jurídico-fundamentais diversas (HEUN, 1992, p. 10). A partir daí, advém a necessidade de desenvolver outras técnicas que compatibilizem a teoria jurídica à nova realidade constitucional pós-positivista visto que a hermenêutica clássica (HERKENHOFF, 2010, p. 13ss) não fornece elementos suficientes para resolver o problema de colisão de direitos, questão que emerge justamente da positivação de valores, por meio de princípios, e da própria força normativa da Constituição.

As hipóteses descritas, marcadas pela ambiguidade da linguagem, lacunas, desacordos morais e colisão de normas, consubstanciam o que costuma se chamar de "casos difíceis"(DWORKIN, 2016, p. 60), para os quais não existe uma solução perfeita e acabada no sistema jurídico, cabendo ao operador do direito desenvolvê-la e justificá-la. Forte, aqui, é a noção de que não existirá uma única resposta correta para todos os casos (ALEXY, 1990, p. 433). Se não houver transparência, a necessária 


\section{O PRINCÍPIO DA PROPORCIONALIDADE À LUZ DA TEORIA DOS LIMITES DOS LIMITES}

hermenêtica de direitos fundamentais pode-se transmudar em uma ferramenta desvantajosa no processo democrático (DALLARI, 2011, p. 299ss). Daí a importância de se definir a o âmbito ou núcleo de proteção e, se for o caso, a fixação precisa das restrições ou das limitações a esses direitos.

\section{Necessidade de Proteção do Conteúdo Essencial dos Direitos Fundamentais}

Os conflitos entre direitos fundamentais não ocorrem apenas nas relações em que o Estado toma parte. Conflitos também se verificam entre titulares de direitos fundamentais, na condição de sujeitos privados, tema inerente à chamada eficácia horizontal dos direitos fundamentais (DUQUE, 2013, p. 102ss). Em que pese as relações privadas não se desenvolverem à luz de uma hierarquia, elas podem conter inegável desigualdade de poder nos seus respectivos polos. Na prática, quanto maior for a desigualdade de poder, maior será a tendência de se verificar lesão aos direitos fundamentais, circunstância que se aplica tanto nas relações verticais, particular -Estado -, quanto nas relações denominadas horizontais - cidadão-cidadão.

Independentemente do tipo de relação analisada, deve-se levar em conta a definição correta em torno da existência de um conflito concreto, sem desconsiderar os limites já impostos pelo legislador para evitar o excesso de subjetividade que agrava o problema, ao invés de solucionálo, preservando-se, assim, o ideal da segurança jurídica. E aqui, fundamental é compreender o que está por trás do âmbito de proteção e cada direito. Entender o que cada direito protege, é um passo importante para evitar pseudo conflitos.

No que concerne à noção de âmbito de proteção, sua eficácia depende do direito fundamental em questão, do âmbito da vida onde se direciona a sua aplicação, bem como da própria situação das partes envolvidas. De modo que um problema comum a todos os direitos fundamentais é a determinação da sua aplicação funcional, que é revelada conforme a compreensão de seu âmbito de proteção e pelo conteúdo essencial do direito fundamental. Isso necessariamente induz a abordagem do âmbito de proteção dos direitos fundamentais para a noção de conteúdo essencial desses direitos (DUQUE, 2013, p. 229).

A defesa do conteúd o essencial dos direitos fundamentais garante um âmbito nuclear de cada direito fundamental de forma pura, a despeito dos interesses gerais empregados para a justificação de restrições, de modo que nenhum direito fundamental pode vir a ser restringido de 


\section{REVISTA ESTUDOS INSTITUCIONAIS}

maneira mais intensa, do que se faça necessário em consideração a interesses coletivos de hierarquia superior ou semelhante (proibição de excesso) [CANARIS, 1999, p. 19ss]. e, assim, toda restrição imposta a um direito fundamental deve ser passível de exame para que seja possibilitado um parâmetro jurídico material para o seu controle judicial (DUQUE, 2013, p. 230-231).

Para esclarecer o nível da gravidade de afetação aos direitos fundamentais, que vão de violações importunas às insuportáveis, em que praticamente anula-se o âmbito de proteção da norma jurídicofundamental, busca-se compreender as circunstâncias do caso concreto (ERICHSEN, 1982, p. 162). Isto demonstra a dificuldade de atuação, já que se enfrenta não apenas a pluralidade de demandas como também a diversidade de situações e a constante mudança das formas de ameaça aos bens tutelados pela constituição (DUQUE, 2013, p. 231). Assim, o reconhecimento em torno da existência de um conteúdo essencial dos direitos fundamentais funciona com uma espécie de barreira ou limite à prática de restrições nesses direitos (DÜRIG, 1953, p. 536).

A definição do conteúdo essencial dos direitos fundamentais procura impedir a sua perda de significado prático, pois restrições desproporcionais no seu âmbito de proteção podem acarretar diversos malefícios, inclusive, o desequilíbrio entre os poderes públicos. Aqui, fala-se na Teoria dos Limites dos Limites, que sustenta que tais restrições são limitadas (MENDES, 2012, p. 56).

A teoria dos limites dos limites, de construção alemã, advoga que as reservas legais que incidem sobre os direitos fundamentais permitem que o legislador intervenha nesses direitos, a fim de que eles sejam restringidos em determinadas situações, sobretudo em face da preservação de outros bens jurídicos relevantes (DUQUE, 2014, 281ss). Nesse contexto, o conceito de limites dos limites refere-se aos limites que vigem para o legislador, no momento em que ele, no curso de sua competência constitucional, restringe os direitos fundamentais (PIEROTH, 2009, p. 285). Tem como fundamento, portanto, impedir que o legislador aja livremente - desprovido de qualquer medida ou moderação - na restrição de direitos fundamentais, a fim de que um conteúdo, considerado como essencial, reste preservado, mesmo após a incidência dessas restrições. Portanto, à luz da teoria dos limites dos limites, o princípio da proteção ao núcleo essencial dos direitos fundamentais deve sempre se associar ao princípio da proporcionalidade. 


\section{O PRINCÍPIO DA PROPORCIONALIDADE À LUZ DA TEORIA DOS}

LIMITES DOS LIMITES

\section{SIGNIFICADO E ALCANCE DO PRINCÍPIO DA PROPORCIONALIDADE}

Neste trabalho, emprega-se a doutrina que trata razoabilidade como sinônimo de proporcionalidade, justamente pela intercambialidade dos conceitos, a despeito de existirem entendimentos em sentido diverso. $\mathrm{O}$ princípio da proporcionalidade tem aplicação clássica no campo do Direito Administrativo (MAURER, 2009, p. 17), mas à partir do século XX vem sendo aplicado com ênfase no Direito Constitucional através da superação de um modelo estritamente legalista/positivista, com o advento do Estado Democrático de Direito. Isso não significa, contudo, que a maior liberdade dada ao juiz na aplicação do Direito é totalmente desvinculada do Direito posto pelo legislador pois o mesmo princípio também se revela como uma barreira ao arbítrio, para evitar o que Paulo Bonavides (2017, p. 430) chama de "Estado de Juízes".

Diante dessas considerações, abordam-se os critérios de exame que integram o princípio da proporcionalidade, enquanto técnica decisória utilizada para solucionar conflitos normativos que envolvam valores impassíveis de resolução apenas com as técnicas tradicionais de hermenêutica, como o que ocorre com a colisão de normas constitucionais. Pautando-se pelo princípio da máxima efetividade da Constituição, exige-se que o intérprete dirija seus esforços para potencializar a efetividade de um direito fundamental sem prejudicar a outra posição jurídica em conflito, de modo que ambas sejam reciprocamente poupadas e compensadas (BARROSO, 2014).

Tenta-se equilibrar os valores conflitantes para que todos eles sejam preservados pelo menos em alguma medida na decisão. $O$ papel do intérprete é justamente harmonizar valores aparentemente contraditórios para apaziguar o conflito. Contudo, em muitos casos essa meta não pode ser atingida uma vez que havendo colisão de direitos, provavelmente um deles será atingido de forma negativa, ainda que parcialmente. Desse modo, surge outra questão a ser trabalhada pelo intérprete, qual seja, dar máxima efetividade a um direito fundamental, restringindo o mínimo possível o outro valor constitucional colidente (BONAVIDES, 2017, p. 279).

As objeções são relevantes e servem de alerta contra retrocessos (DUQUE, 2013, p. 181ss). O presente estudo defende que os direitos fundamentais são normas jurídicas de máxima hierarquia. Portanto, todas as restrições ao seu âmbito de proteção devem passar por um exame constitucional mais rigoroso na instância Judiciária, a qual cabe 


\section{REVISTA ESTUDOS INSTITUCIONAIS}

JULHO/DEZEMBRO - ISSN 2447-5467

exigir demonstrativos de que a limitação se justifica diante de interesses mais relevantes. Compreender a compatibilidade das restrições a partir de um juízo quanto à sua proporcionalidade é uma meta incessante no âmbito do Direito Constitucional moderno.

Em resumo, o critério da proporcionalidade atua como diretriz à atividade interpretativa, ao elucidar questões conflituosas e também como filtro de escolha entre princípios que pautam sua aplicacão. Esse posicionamento funda-se na concepcão moderna do Direito, da qual se depreende um conceito aberto de normas, diante da complexidade das relacões sociais de nosso tempo. Destaca-se, assim, a normatizacão de condutas com base em parâmetros definidos por normas principiológicas, que, apesar do grau de abstração, contam com existência objetiva (TAVARES, 2008, p. 712).

Dentro desse contexto, o critério da proporcionalidade representa um importante instrumento de solucão de conflitos visto que se mostra como critério de sopesamento de princípios colidentes em dada situacão concreta. Ainda assim, encontram-se críticas à sua aplicacão, críticas essas, referentes à subietividade das decisões pautadas na proporcionalidade, à indeterminacão e à autonomia que é dada aos iuízes nas decisões de controvérsias. Não nos rendemos a elas, apesar de considerá-las alertas contra eventuais regressos democráticos, pois a atuacão criativa do intérprete, desde que filtrada por argumentos constitucionais, é indispensável.

É neste ponto que a teoria dos limites dos limites foi desenvolvida pela doutrina e jurisprudência para agregar significado à disposição constitucional prevista no art. 19, II da Lei Fundamental alemã, segundo a qual em "nenhum caso um direito fundamental pode ser violado em seu conteúdo essencial" (STERN, 1994, p. 865ss). Trata-se de entendimento que vem encontrando ampla aplicação no direito constitucional pátrio. A ideia é que que as leis que justificam restrições aos direitos fundamentais sejam limitadas pelos direitos restringidos, atingindo-se, assim, parâmetros razoáveis de fruição simultânea desses direitos. Em outras palavras, o conceito de limites dos limites refere-se aos limites que vigem para o legislad or, no momento em que ele, no curso de sua competência constitucional, restringe os direitos fundamentais (PIEROTH; SCHLINK, 2009, p. 285).

Para Robert Alexy (1994), a ponderação realiza-se em três planos. Primeiro, define-se a intensidade da intervenção. Após, perquire-se a importância dos fundamentos justificadores da intervenção. Por fim, realiza-se a ponderação em sentido específico e estrito. Em resumo, o exame da adequação indica o que é apto a alcançar o resultado pretendido, o exame da necessidade, a aferição da inexistência de outro 


\section{O PRINCÍPIO DA PROPORCIONALIDADE À LUZ DA TEORIA DOS LIMITES DOS LIMITES}

meio menos gravoso e a proporcionalidade em sentido estrito, a averiguação da relação custo-benefício. Cabe a análise de cada um desses elementos de forma pormenorizada.

\section{Exame de Adequação}

O exame da adequação ou da idoneidade do meio que promove a restrição de um direito fundamental questiona se a medida mostra-se útil para a obtenção da finalidade por ela pretendida. A determinação de um meio adequado requer uma decisão política, que pode englobar aspectos econômicos, sociais, jurídicos e até mesmo técnicos, restringindo-se o espaço de intervenção do tribunal constitucional. Consequentemente, não se suscita a fruição de um meio que não possa realizar a finalidade desejada (DUQUE, 2013, p. 395-396).

Assim, a adequação exige a idoneidade e legitimidade constitucional de uma medida restritiva de direitos fundamentais, para ser válida ao aferir sua idoneidade no atendimento de uma finalidade constitucionalmente legítima (MARMELSTEIN, 2016, p. 391). Supõe-se, ainda, a justiça pela constatação de equilíbrio, moderação e harmonia em detrimento de condutas meramente caprichosas. O elemento da adequacão (ou da conformidade) dos meios trata, portanto, da necessária correlacão entre os meios e os fins a serem atingidos, para que os meios escolhidos sejam aptos a atingir o fim determinado.

Como já referido, decompôs-se o princípio em três subprincípios: adequação, necessidade e proporcionalidade em sentido estrito. Estes são os elementos da razoabilidade do ato que indicam uma relação racional e proporcional entre os motivos, meios e fins a ele subjacentes. Na sequência, tem-se análise pormenorizada do subprincípio da necessidade.

\section{Exame de Necessidade}

O exame da necessidade questiona a existência de medidas alternativas, igualmente aptas para se chegar ao resultado perseguido, porém menos restritivas aos direitos em jogo. Ser necessário significa, na prática, que não se vislumbram outras possibilidades, menos impactantes nos âmbitos da vida protegidos pelos direitos fundamentais. Gilmar Mendes (2012, p. 25) ressalta que, "na prática, adequação e necessidade não têm o mesmo peso ou relevância no juízo da ponderação. Assim, apenas o que é adequado pode ser necessário, mas o que é necessário não pode ser inadequado". Tal consideração decorre, acima de tudo, na 


\section{REVISTA ESTUDOS INSTITUCIONAIS}

natureza escalonada do exame, levando-se em conta que, invariavelmente, o juízo de adequação deve preceder $o$ de proporcionalidade.

Fica evidente que a análise da necessidade se diferencia da adequação na medida em que este refere-se à relação de meio e fim entre a medida e o objetivo, enquanto que aquele considera ainda eventuais medidas alternativas para se atingir o mesmo fim, sendo imprescindivelmente comparativo (SILVA, 217, p. 170ss). O grande problema do exame da necessidade é que a busca de uma medida menos restritiva pode apontar para opções que, do ponto de vista prático, tem sua implementação inviabilizada por questões técnicas ou econômicas. Surge, aqui, um problema de difícil equacionamento, pelo fato de que o poder judiciário não pode obrigar o Poder Executivo a implementar uma medida que comprometa, significativamente, seu orçamento. Hipótese contrária representaria incontestável invasão no princípio da separação dos poderes (DUQUE, 2017, p. 214ss). Trata-se de questão que só pode vir a ser analisada levando em consideração as circunstâncias fáticas e jurídicas do caso concreto.

Em análise aos embargos de declaração na ADI 3.460 ED/DF, de relatoria do Ministro Teori Zavascki discutiu-se se, em matéria de direito constitucional e direito processual civil, o pedido de habilitação do amicus curiae precisa ser apreciado antes do julgamento. Em razão da natureza instrutória de sua participação, eventual dispensa não acarretaria prejuízo, não ensejando recurso de modo que não se constatou nulidade no acórdão recorrido.

Ao negar legitimidade recursal entendeu-se, por meio da ponderação expressa pelos critérios de adequação e necessidade, que o amicus curiae é um colaborador da justiça que não se vincula processualmente ao resultado do julgamento sendo sua presença um benefício para a iurisdicão e não um direito subietivo processual do interessado. "A decisão que recusa pedido de habilitacão de amicus curiae não compromete qualquer direito subietivo, nem acarreta qualquer espécie de prejuízo ou de sucumbência ao requerente".

Por fim, a razoabilidade deve abranger, ainda, a ideia de proporcionalidade em sentido estrito, consistente na ponderação entre o ônus imposto e o benefício trazido, para constatar se a medida é legítima. O princípio da proporcionalidade é, então, utilizado como instrumento de ponderação entre valores constitucionais colidentes. É o que se analisa a seguir. 


\section{O PRINCÍPIO DA PROPORCIONALIDADE À LUZ DA TEORIA DOS LIMITES DOS LIMITES}

\section{Exame de Proporcionalidade em Sentido Estrito}

Finalmente, o terceiro critério ou elemento de concretização do princípio da proporcionalidade consiste em uma técnica decisória utilizada para solucionar conflitos normativos que envolvam valores ou opções políticas, em relação aos quais as técnicas tradicionais de hermenêutica não se mostram eficientes ou mesmo suficientes, como o que ocorre com a colisão de normas constitucionais. Neste sentido, a ponderação pode ser encarada como um dever de argumentar com transparência, forçando o julgador a expor todos os motivos relevantes que o levaram a decidir em favor de um ou te outro princípio constitucional (MARMELSTEIN, 2016, p. 391).

Não é por menos que a preocupação com as consequências práticas das decisões judiciais é um fato que tem despertado apreensões de todo o tipo na comunidade jurídica. Prova disso é o esforço do legislador em propor uma aplicação do direito voltada à segurança. A Lei 13.655 de 2018, que atualizou a lei de Introdução às Normas do Direito Brasileiro ${ }^{3}$ é o maior exemplo dessa realidade, ainda que não se saiba, ao certo, o modo pelo qual ela será implementada.

Em verdade, os esforços jurídicos tentam equilibrar os valores conflitantes para que todos eles sejam preservados pelo menos em alguma medida na decisão. $O$ papel do intérprete é justamente harmonizar valores aparentemente contraditórios para apaziguar o conflito. Contudo, em muitos casos essa meta não pode ser atingida uma vez que havendo colisão de direitos, provavelmente um deles será atingido de forma negativa, ainda que parcialmente. Desse modo, surge outra questão a ser trabalhada pelo intérprete, qual seja, dar máxima efetividade a um direito fundamental, restringindo o mínimo possível o outro valor constitucional colidente (BONAVIDES, 2017, p. 406).

Conclui-se, então, que o princípio da razoabilidade ou da proporcionalidade permite ao Judiciário anular atos quando não haja adequação entre o fim perseguido e o meio empregado, quando a medida não seja exigível ou tampouco necessária e, ainda, quando a perda é mais considerável do que o ganho. Assim, o magistrado deve atentar-se para não impor seus próprios juízos de conveniência e oportunidade sob o véu

\footnotetext{
3 Art. 20 do Decreto-Lei 4.657/1942, com redação dada pela Lei 13.655 de 2018. “Nas esferas administrativa, controladora e judicial, não se decidirá com base em valores jurídicos abstratos sem que sejam consideradas as consequências práticas da decisão. Parágrafo único. A motivação demonstrará a necessidade e a adequação da medida imposta ou da invalidação de ato, contrato, ajuste, processo ou norma administrativa, inclusive em face das possíveis alternativas".
} 


\section{REVISTA ESTUDOS INSTITUCIONAIS}

da finalidade legítima, cabendo a ele desconstituir apenas o que seja manifestamente incompatível com a ordem jurídica constitucional ou que estejam em colisão.

Com base nesses parâmetros, toda medida restritiva a direitos fundamentais, que não se mostre adequada, ou necessária ou proporcional em sentido estrito, será considerada excessiva e, portanto, desproporcional. Não se poderá, nesse caso, advogar sua compatibilidade com a Constituição, servindo a teoria dos limites dos limites como critério hábil a propor discussões em torno dos limites impostos aos poderes públicos, na conformação das liberdades.

\section{CONSIDERAÇõES FINAIS}

O pós-positivismo traduz-se na superação do legalismo estrito, pelo reconhecimento de valores que passam a integrar o ordenamento jurídico, ainda que implicitamente. Sendo assim, os princípios ganham força normativa e vinculativa, garantindo, de modo eficaz, a unidade do Direito em um Estado que se pretende democrático e pluralista, condicionando a atividade do intérprete. A Constituição passa a ser o centro do sistema. Nesse ambiente, a colisão desses princípios é inevitável.

Desse modo, busca-se preservar o núcleo fundamental de cada princípio, enquanto expressão dos direitos fundamentais contra arbitrariedades causadas pelo excesso de subjetivismo na interpretação da norma pelos operadores jurídicos. Suas decisões devem considerar a norma e os fatos, em uma análise argumentativa e interativa, apta a produzir a solução justa para o caso concreto. Há dois princípios que ganharam destaque nesse atual cenário brasileiro: 0 da proporcionalidade e o da dignidade da pessoa humana. Este, ainda perquirindo maior definitividade conceitual, mas com inegável relevância; aquele, sofrendo apenas críticas isoladas, em caráter minoritário, viabilizam a solução dos chamados casos difíceis.

Procurou-se, assim, neste trabalho, definir contornos que permitam aplicações práticas desses princípios, pautadas tanto pela dimensão abstrata quanto pelas motivações racionais e fundamentadas das decisões judiciais, de modo que o princípio da proporcionalidade atuaria, em última análise, como critério para definir o limite dos limites às restrições, inviabilizando restrições que, ao suprimir o conteúdo essencial dos direitos fundamentais, os descaracterizaria como tal.

Busca-se, assim, demonstrar que o princípio da razoabilidade ou da proporcionalidade permite ao Judiciário anular atos quando não haja adequação entre o fim perseguido e o meio empregado, quando a medida 
não seja exigível ou tampouco necessária e, ainda, quando a perda é mais considerável do que o ganho. Assim, quem tem o poder de decidir deve atentar-se para não impor seus próprios juízos de conveniência e oportunidade sob o véu da finalidade legítima, cabendo a ele desconstituir apenas o que seja manifestamente incompatível com a ordem jurídica constitucional.

\section{REFERÊNCIAS}

ALEXY, Robert. Theorie der Grundrechte. Baden-Baden: Suhrkamp, 1994.

ALEXY, Robert. Theorie der juristischen Argumentation. Die Theorie des rationalen Diskurses als Theorie der juristischen Begründung. 2. Auf. Frankfurt: Suhrkamp, 1990.

ÁVILA, Humberto. Segurança Jurídica. Entre permanência, mudança e realização no Direito Tributário. São Paulo: Malheiros, 2011.

ÁVILA, Humberto. Teoria dos princípios: da definição à aplicação dos princípios jurídicos. 6 ed. São Paulo: Malheiros, 2006.

\section{BARROSO, Luís Roberto. O Novo Direito Constitucional}

Brasileiro: contribuições para a construção teórica e prática da jurisdição constitucional no Brasil. Belo Horizonte: Fórum, 2014. 3 reimpressão.

BONAVIDES, Paulo. Curso de Direito Constitucional. 32. ed. São Paulo: Malheiros, 2017.

CANARIS, Claus-Wilhelm. Grundrechte und Privatrecht. Eine Zwischenbilanz. Berlin: Gruyter, 1999.

DALLARI, Dalmo de Abreu. Elementos de Teoria Geral do Estado. 30. ed. São Paulo: Saraiva, 2011. 


\section{REVISTA ESTUDOS INSTITUCIONAIS}

DI FABIO, Udo. Zur Theorie eines grundrechtlichen Wertesystems. In: MERTEN, Detlef; PAPIER, Hans-Jürgen (Hrsg.) HDG. B.. II. Heidelberg: Müller, 2006, p. 1.031-1.057.

DUQUE, Marcelo Schenk. Direito Privado e Constituição: Drittwirkung dos direitos fundamentais. Construção de um modelo de convergência à luz dos contratos de consumo. São Paulo: Revista dos Tribunais, 2013.

DUQUE, Marcelo Schenk. Curso de Direitos Fundamentais: teoria e prática. São Paulo: Revista dos Tribunais, 2014.

DUQUE, Marcelo Schenk. O Exame da necessidade das medidas impostas pelo Poder público. In: HEINEN, Juliano; OHLWEILER, Leonel Pires; RAMOS, Rafael (Org). Fundamentos do Direito Administrativo Contemporâneo. Porto Alegre: Sapiens, 2017, p. 214-243.

DÜRIG, Günter. Bedürfnis und öffentliches Interesse als Rechtsbegriffe. JZ. Tübingen: Mohr, 1953, p. 535-537.

DWORKIN, Ronald. A Justiça de Toga. São Paulo: Wmfmartinsfontes, 2016. Tradução de: Jefferson Luiz Camargo.

ERICHSEN, Hans-Uwe. Staatsrecht und Verfassungsgerichtsbarkeit. 3., völlig neu bearbeitete Auf. München: Beck, 1982, V. I.

GADAMER, Hans-Georg. Wahrheit und Methode. Grundzüge einer philosophischen Hermeneutik. 6. durchgesehene Auf. Tübingen: Mohr, 1990, B. I.

GRIMM, Dieter. Rückkehr zum liberalen Grundrechtsverständnis? In: GRIMM, Dieter. Die Zukunft der Verfassung. Frankfurt: Suhrkamp, 1991, p. 221-240. 
HÄBERLE, Peter. Der Sinn von Verfassungen in Kulturwissenschaftlicher Sicht. AöR, B. 131. Tübingen: Mohr, 2006, p. 621-642.

HERKENHOFF, João Batista. Como Aplicar o Direito: à luz de uma perspectiva axiológica, fenomenológica e axiológico-política. 12. ed. Rio de Janeiro: Gen/forense, 2010. 179 p.

HESSE, Konrad. Die Normative Kraft der Verfassung. Freiburger Antrittsvorlesung. In: Recht und Staat, Heft 222. Tübingen: Mohr, 1959.

HESSE, Konrad. Grundzüge des Verfassungsrechts der Bundesrepublik Deutschland. Neudruck der 20. Auf. Heidelberg: Müller Verlag, 1999.

HEUN, Werner. Funktionell-rechtliche Schranken der Verfassungsgerichtsbarkeit. Reichweite und Grenzen einer dogmatischen Argumentationsfigur. Baden-Baden: Nomos, 1992.

LASSALLE, Ferdinand. A essência da Constituição. 6 ed. Rio de Janeiro: Lumen Juris, 2001.

LERCHE, Peter. Übermaß und Verfassungsrecht. Zur Bindung des Gesetzgebers an die Grundsätze der Verhältnismäßigkeit und der Erforderlichkeit. Köln: Carl Heymann, 1961.

MANGOLDT, Hermann von; KLEIN, Friedrich. Kommentar zum Grundgesetz. 2. Auf. Berlin und Frankfurt.: Vahlen, B. I, 1957.

MARMELSTEIN, George. Curso de Direitos Fundamentais. 6. ed. São Paulo: Gen, 2016. 


\section{REVISTA ESTUDOS INSTITUCIONAIS}

MAURER, Hartmut. Allgemeines Verwaltungsrecht. 17. überarbeitete und ergänzte Auf. München: Beck, 2009.

MENDES, Gilmar Ferreira. Direitos Fundamentais e Controle de Constitucionalidade. 4 ed. São Paulo: Saraiva, 2012.

PIEROTH, Bodo; SCHLINK, Bernhard. Grundrechte Staatsrecht II. 25. neu Auf. Heidelberg: Müller, 2009.

SARLET, Ingo Wolfgang. A eficácia dos direitos fundamentais. Uma teoria geral dos direitos fundamentais na perspectiva constitucional. 11 ed. Porto Alegre: Livraria do Advogado, 2012.

SILVA, Virgílio Afonso da. Direitos Fundamentais: conteúdo essencial, restrições e eficácia. 2. ed. São Paulo: Malheiros, 2017.

SILVEIRA, José Néri da. A Função do Juiz. Palestra proferida no Recife, a convite da Escola Superior da Magistratura de Pernambuco, no Curso de Processo Civil, em 06.12.1991. Recife: [s.ed.], 1991.

STERN, Klaus. Das Staatsrecht der Bundesrepublik Deutschland: Allgemeine Lehren der Grundrechte. München: Beck, 1994, B. III/2.

TAVARES, André Ramos. Curso de Direito Constitucional. 6. ed. São Paulo: Saraiva, 2008.

ZIPPELIUS, Reinhold. Wertungsprobleme im System der Grundrechte. Beck. München: 1962.

RECEBIDO EM: 22/11/2018.

ACEITO EM: 10/12/2018. 